\title{
Detection of mold species in poultry farms in refer to their virulence potential
}

\author{
Shaimaa Mohamed ${ }^{1}$, Amal Awad $^{1}$, Youssef Elsaedy ${ }^{2}$, Gamal Younis $^{1}$ \\ ${ }^{1}$ Department of Bacteriology, Mycology and Immunology, Faculty of Veterinary Medicine, Mansoura University, 35516, Egypt. \\ ${ }^{2}$ Department of Physiology, Faculty of Veterinary Medicine, Mansoura University, 35516, Egypt.
}

\section{ARTICLE HISTORY}

Received: 02.01.2020

Revised: 30.01 .2020

Accepted: 23.03 .2020

Address correspondence to Shaimaa Mohamed; Tel: +201094975729; E-mail: shemashema12@yahoo.com

\section{ABSTRACT}

\begin{abstract}
Objective: The aim of the present study was to isolate and identify mold species from poultry farms with detection of their virulence potential, biofilm formation capability and to perform antifungal susceptibility testing to some representative isolates.

Design: Observational study.

Animals: Fifty, freshly dead broiler chicks.

Procedures: A total of 250 samples were collected from 50 diseased chicks $(5$ samples each), including lung, liver, kidney, heart, and tracheal swap. In addition, litter samples were collected from 7 poultry farms and were subjected to mycological examination. The isolated mold species have been tested for hemolytic activity, catalase, amylase, lipase, and biofilm production activity; besides, detection of virulence genes (rhbA, fos1 , and pskB) using PCR assay. .

Results: A total of 208 mold isolates were identified, with five genera; Aspergillus (84.6\%), Zygomycetes (12.9\%), Acremonium (0.96\%), Penicillium (0.96\%) and Alternaria (0.48\%). Mold isolates displayed various degrees of fungal activities on blood agar plates, catalase activity, amylase activity, lipase activity, and the ability for biofilm production in vitro. Regarding the selected virulence genes, fos-1 was detected in A.fumigatus ( 3 isolates) and A.flavus (2isolates). While pksP gene was detected in A.fumigatus ( 7 isolates) and A.niger ( 2 isolates) and rhbA detected in A. fumigatus (8 isolates) and one isolate of $A$. flavus of the total evaluated species. The MIC determination provide evidence for the high resistance of all evaluated isolates to nystatin, and a relatively higher sensitivity was displayed by clotrimazole followed by ciclopiroxolamine and tioconazole.

Conclusion and clinical relevance: The results reveal that most of the fungal isolates tested displayed enzymatic activity, which are the most effective virulence factors contributing to fungal pathogenicity and high resistance to antifungal, which represents a potential public health concern.
\end{abstract}

Keywords: Molds, Broiler chicks, Antifungals, Enzymatic activity, Virulence genes.

\section{INTRODUCTION}

Fungal/mycotic diseases cause significant economic losses to the poultry industry either due to their direct infectious nature or due to the production of mycotoxins. They induce high morbidity and mortality in young birds, stunted growth, and diarrhea. Mycotic infections in poultry are frequently associated with immunosuppression, which predisposes many bacterial and viral infections [1]. In addition, some fungi such as Aspergillus species have significant public health importance, especially in immunocompromised patients [2].

The source of infection to poultry farms occur either via using of a moldy litter or from hatcheries facilities when oneday-old birds have retained conidia arrived at the farms. Other sources of farm contamination may occur through poor quality feedstuffs, improper bedding management, the entrance of air loaded with conidia [3, 4]. In poultry farms, humidity, and temperature conditions stimulate the hyphal growth and multiplication of fungi leading to the huge production of conidia, which are subsequently spread and inhaled by the birds [5].

Virulence factor is a microbial element causing host damages and considered a determinant of pathogenicity [6]. Fungi produce an array of extracellular hydrolytic enzymes, such as lipases, proteases, and phospholipases. These enzymes play an essential role in fungal pathogenicity, such as in fungal nutrition, tissue damage, iron acquisition fungal dissemination within the human body, and overcoming the host immune system [7]. Fungal hydrolytic enzymes not only facilitate easier tissue invasion but also they could impair 
some mechanisms of the immune system and assist in obtaining nutrients, subsequently causing damage to the host [8]. Additionally, fungi possessing several genes and proteins associated with their pathogenicity [9], fos-1 is a gene encoding a putative two-component histidine kinase which responsible for osmotic change adaptation regulation, while, $p k s P$, a putative polyketide synthase encoding gene, involved in pigment biosynthesis [10]. The expression of $p k s P$ detected in vitro and in vivo has been previously studied by Tsai et al. [11] who found transcripts of $p k s P$ only during conidiation and not in the hyphal stage by northern blot. The Rheb proteins comprise a family of Ras-related proteins that exhibit deviations from the consensus amino acid sequence in the first GTP-binding domain, as well as in the effector domain [12]. In a previous study, Panepinto et al. [13] created a strain that lacks $r h b A$ gene, the $\triangle r h b A$ mutant displayed a considerable reduction in virulence compering with the wild virulence type.

Biofilms are defined as a community of microorganisms that are attached to a surface and embedded in an extracellular polysaccharide matrix, which facilitates the adherence of these microorganisms to biomedical surfaces concentrate the enzymes produced during the growth which helps in further tissue invasion and protect them from host immune system and antimicrobial therapy and associated with a variety of chronic and persistent infections. The infections associated with biofilm formation are difficult to be cured with existing drug therapies which leads to a high mortality rate [14].

Antifungal susceptibility tests are very important tools to direct the treatment of fungal diseases, to detect antifungals resistance, and to recognize disease epidemiology [15]. The resistance in fungi may be developed due to excessive use of drugs in farm or due to genetic mutation of the drug target in fungi- or due to secretion of the fungal enzyme such as $14-\alpha$ sterol demethylase which are responsible for the resistance to azole drugs. In addition, there are other mechanisms of antifungal resistant include increased efflux pump activity and decreased target enzyme affinity, also in vivo, there are mechanisms of antifungal resistance such as biofilm formation, which protects fungi from the action of antifungals [16-20].

Thus, the current study was planned for the mycological examination of diseased chicks as well as poultry litter to recognize the possible occupational exposure of poultry farmworkers to fungi and their metabolites from poultry farms located at Dakahalyia governorate, Egypt with detection of its virulence determinants and to determine its susceptibility to antifungal agents.

\section{MATERIALS AND METHODS}

\subsection{Samples collection}

Tissue samples including liver, lungs, heart, kidneys as well as tracheal swab samples were collected from 50 freshly dead chicks collected from seven different chicken poultry farms located in the district of Mansoura City, Egypt, during the period from July to December 2017. On necropsy, the most common lesions detected were congestion in the lung associated with the presence of nodule in lung tissue. In addition, litter samples were collected from the visited farms. Each sample was kept separately in a sterile plastic bag, and the bags were labeled and kept on ice containers and transported to the laboratory for mycological examination.

\subsection{Isolation and identification of fungal isolates}

From each chicken visceral organ, tissue specimen was cultured after being touched by flamed spatula then homogenized before inoculation. Tracheal swabs were streaked with the cotton swaps and litter samples directly streaked onto SDA (cat. No. CM2497E) and PDA (was made by mixing $200 \mathrm{gm}$ potato infusion, agar (15 g) and dextrose (20g) plates supplemented with chloramphenicol to inhibit bacterial growth, each sample was cultured onto two plates to be incubated at $25^{\circ} \mathrm{C}$ and $37^{\circ} \mathrm{C}$ and checked daily for any fungal growth until ten days [21]. The isolated fungi were identified macroscopically by observing colony characters and colony reverses in the inoculated plates and microscopically using scotch tape preparation stained with lactophenol cotton blue stain [22].

\subsection{Blood Hemolysis test:}

Determination of hemolysin activity was evaluated with a blood plate assay, according to Manns et al. [23] using PDA supplemented with $7 \%$ fresh sheep blood and $3 \%$ glucose [24].

\subsection{Detection of mold enzymatic activity}

Amylase production was evaluated using the starch agar plate method, as described by SB et al. [25]. In brief, fungal isolates were inoculated into potato dextrose agar supplemented with $1 \mathrm{~g}$ of starch. Lugol's iodine solution was added to the culture plate to identify the zones around the cultures. Additionally, Catalase activity was assessed by using the $\mathrm{H}_{2} \mathrm{O}_{2}$ solution, according to Zohri et al. [26]. Furthermore, lipolytic activity was determined, as described by Alapont et al. [27]. In brief, agar plates containing Tween 80 were prepared. Positive results were observed by the formation of white precipitation along the periphery of the colony.

\subsection{Biofilm production}

The ability of biofilm formation was determined by tube adherence test, according to Dag et al. [28], by using $2 \%$ safranin. They were then examined for the presence of an adherent layer. Biofilm production was scored as negative (), weakly positive $(+)$, or strong (++) positive.

\subsection{Determine Minimal inhibitory concentration (MIC)}

The activity of fungal isolates was evaluated against clotrimazole, tioconazole, ciclopiroxolamine, fluconazole, and nystatin. A stock solution was prepared from each antifungal drug to get a final concentration of $1000 \mu \mathrm{g} / \mathrm{ml}$ and kept at $4{ }^{\circ} \mathrm{C}$ until assayed. MIC for each fungal isolate was evaluated according to the method described by Ochei et al. [29] and Agbulu et al. [30]. 


\subsection{PCR amplification and gel electrophoresis}

In total, 49 fungal isolates were screened for the presence of three virulence-associated genes. The isolates including, A. fumigatus (9 isolates), Zygomycetes (9 isolates), A.niger (8 isolates), A. flavus (9 isolates), A. terreus (5 isolates), A. glaucus ( 3 isolates), $A$. nidulans (one isolate), Acremonium (Two isolates), Penicillium (Two isolates); and Alternaria (Two isolates). Fungal DNA was extracted by the QIAamp DNeasy Plant Mini kit (Catalogue no. M501DP100). PCR was carried for detection of three virulence genes including, fos-1 encoding a putative two-component histidine kinase, PksP encoding Polyketide synthase (DHN-melanin synthesis) and $r h b A$ is a Ras-related protein. Primer pairs used [31]. (target genes, sequences, and PCR products) are summarized in Table 1. PCR was performed in a volume of 25 $\mu \mathrm{L}$ consisting of $12.5 \mu \mathrm{L}$ of $2 \mathrm{X}$ ABT Red Master Mix (Cat. No ABT003), $1 \mu \mathrm{L}$ of each diluted primer, and $5 \mu \mathrm{L}$ DNA template, nuclease-free water was used for complete the volume into $25 \mu \mathrm{L}$. PCR program was conducted, as mentioned by the referred authors for each gene (Table 1 ). The PCR products were fractionated on a $1.2 \%$ agarose gel using a $1 \mathrm{X}$ TBE buffer containing $3 \mu \mathrm{L}$ ethidium bromide and using ABT100bp plus DNA ladder (Cat. No ABT011) and were visualized under UV light, and the gels were photographed using a UV gel documentation system.

\section{RESULTS}

In total, 208 isolates were identified by macroscopic and microscopic examination including, 196 isolates from the diseased birds and 12 isolates from litter samples. Five genera were identified: Aspergillus (84.6\%), including six species $(A$. fumigatus (32.69\%), A. flavus (20.6\%), A. niger (26.9\%), $A$. terreus (2.4\%), A. glaucus (1.4\%), and A.nidulans $(0.48 \%)$, Zygomycetes (12.9\%) including Mucor and Rhizopus, Acremonium (0.96\%), Penicillium (0.96\%) and Alternaria (0.48\%) (Table 2).

The distribution of fungal isolates in different samples is presented in Table 2, Nineteen $A$. fumigatus isolates were recovered from the lung tissue. The prevalence of $A$. fumigatus was higher in winter than in hot climate followed by $A$. niger (15 isolates) and $A$. flavus (11 isolates), Zygomycetes ( 6 isolates), A. terreus and A.glaucus ( 2 isolates each), Acremonium, $A$. nidulans and Penicillium spp (one isolate each). In tracheal swaps, $A$. niger was the most prevalent isolates ( 8 isolates) followed by A. Fumigatus (6 isolates), A.flavus (5 isolates), Zygomycetes (3 isolates) and one isolate of Penicillium. In the examined heart samples, $A$. fumigatus (16 isolates) was the most common isolates followed by $A$. flavus ( 6 isolates), then $A$. niger ( 5 isolates), zygomycetes, $A$. terreus and $A$. glaucus (one isolate each). Regarding liver samples, $A$. fumigatus (14 isolates) was the most prevalent, followed by A. flavus (10 isolates), A. niger ( 9 isolates), and Zygomycetes (4 isolates). Finally, in kidney samples, $A$. niger was the most prevalent isolates (16) followed by $A$. fumigatus ( 9 isolates) and $A$. flavus ( 9 isolates), then Zygomycetes ( 6 isolates), Acremonium, A. terreus, and Alternaria (one isolate each).
Fungal isolates were plated on a blood agar plate for the detection of their hemolytic activity. Fungal isolates displayed various degrees of fungal activities on blood agar plates, $22 \%$ of $A$. fumigatus $39 \%$ A. niger $18.6 \%, A$. flavus $33 \%$ Zygomycetes displayed hemolysis on blood agar plates. Catalase activity has been revealed by $A$. fumigatus (45.5\%), A. niger (57\%), A. flavus (60\%), A. terreus (20\%), Zygomycetes $100 \%$, Penicillium $50 \%$. While, amylase activity was displayed by $A$. fumigatus 66\%, A. niger (64\%), A. flavus (46.8\%), $A$. glaucus (33\%), Acremonium (100\%), Penicillium 50\%. In addition, lipase activity was detected by $A$. fumigatus (47\%), A. niger (66\%), A. flavus (58\%). A.terreus (20\%), Zygomycetes (11\%). Biofilm production in vitro has been displayed by $A$. fumigatus (86.7\%), A. niger (78.5\%), A. flavus (79\%), A. terreus 20\%, Acremonium (50\%), Penicillium (50\%), Zygomycetes (14.8\%) (Table 3).

Regarding litter samples, A. fumigatus, A. flavus, A. niger, and mucor spp were isolated. Interestingly, A. niger and $A$. fumigatus were common isolates from both birds samples and litter samples. A. fumigatus was isolated from straw, deep litter, and rice husk type, while, $A$. niger was isolated from the same samples as well as sawdust. On the other hand, Zygomycetes were isolated from deep litter and sawdust, while $A$. flavus was isolated from rice husk litter. The prevalence of fungi was higher in straw, deep litter, hay than sawdust.

In total, Aspergillus species were the most predominate isolates including, $A$. fumigatus (68; 32.69\%), A. niger (56; $26.92 \%)$, A. flavus (56; 26.92\%), A. terrus (5; 2.4\%) A. glaucus, A. nidulans $(1 ; 0.48 \%)$, followed by Zygomycetes $(27 ; 12.9 \%)$; while the prevalence of Penicillium, Alternaria, and Acremonium were $0.96 \%, 0.96 \%$, and $0.48 \%$, respectively (Table 3).

In total, 49 representative isolates were screened for the presence of three virulence genes. A. fumigatus (9 isolates), Zygomycetes (9 isolates), A. niger (8 isolates), A. flavus ( 9 isolates), A. terreus (5 isolates), A. glaucus (3 isolates), A. Nidulans (one isolate), Acremonium (Two isolates), Penicillium (Two isolates), Alternaria (Two isolates). Regarding fos-1 gene, it was detected in A. fumigatus (3 isolates) and A.flavus (Two isolates), rhbA was detected in $A$. fumigatus ( 8 isolates) and one isolate of $A$. flavus, while, $P k s p$ 2 was determined in $A$. niger ( 2 isolates) and seven isolates of A. fumigatus (Table 4).

The susceptibility testing of antifungal drugs was carried out using the agar dilution method. As it shown in Table 5, Minimum Inhibitory concentration (MIC) for clotrimazole 125 $\mu \mathrm{g} / \mathrm{mL}$ with $A$. niger and $A$. flavus and $500 \mu \mathrm{g} / \mathrm{ml}$ on $A$. fumigatus and $250 \mu \mathrm{g} / \mathrm{mL}$ on A. glaucus and $1000 \mu \mathrm{g} / \mathrm{mL}$ on Acremonium and Zygomycetes, while, ciclopiroxolamine 125 $\mu \mathrm{g} / \mathrm{mL}$ on $A$. niger and $A$. terrus and $1000 \mu \mathrm{g} / \mathrm{ml}$ on A. flavus, and $500 \mu \mathrm{g} / \mathrm{mL}$ on $A$. fumigatus and $A$. niger, tioconazole $1000 \mu \mathrm{g} / \mathrm{mL}$ A. glaucus, A. nidulans and A. flavus $125 \mu \mathrm{g} / \mathrm{mL}$ on $A$. terreus, fluconazole only affect Acremonium with a concentration of $1000 \mu \mathrm{g} / \mathrm{Ml}$. All fungal isolates were resistant to nystatin. Aspergillus species and Zygomycetes were resistant to fluconazole. While Acromonium isolates 
were susceptible to fluconazole $(1000 \mu \mathrm{g} / \mathrm{mL})$. Zygomycetes showed more resistance to clotrimazole, tioconazole, ciclopiroxolamine than the relatively more susceptible Aspergillus spp. (MIC $125-1000 \mu \mathrm{g} / \mathrm{mL}$ ).

Table 1. Oligonucleatide primers sequences used in this study.

\begin{tabular}{llll} 
Protein & Target gene & Primer sequences & Amplicon \\
Histidine kinase & $f o s-1-F$ & ATGCACATATTGCTGGTGGA & 424 \\
& $f o s-1-R$ & AATCAGGTCTTGTCCCAACG & \\
Polyketide synthase & $p k s P-F$ & AGCGACGACTACCGTGAGAT & \multirow{2}{*}{398} \\
& $p k s P-R$ & AGAATGGGATCGTTGTCAGC & \\
Ras-related protein & $r h b A-F$ & TGGGCAAATCGTCTCTTACC & 414 \\
& $r h b A-R$ & AGTCGAGACGAGCACTAGC &
\end{tabular}

Table 2. Prevalence of different fungal isolates in the tested birds and litter samples.

\begin{tabular}{|c|c|c|c|c|c|c|c|c|c|c|c|c|}
\hline Samples & 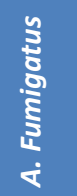 & 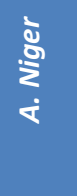 & $\begin{array}{l}\frac{u}{3} \\
\frac{8}{4} \\
\dot{4}\end{array}$ & $\begin{array}{l}\stackrel{u}{S} \\
\stackrel{5}{N} \\
\dot{\leftarrow}\end{array}$ & $\begin{array}{l}\text { ș } \\
\text { ș } \\
\frac{0}{\sigma} \\
\dot{x}\end{array}$ & 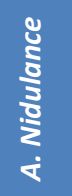 & 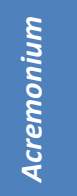 & 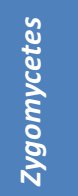 & 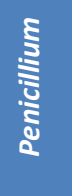 & $\frac{8}{\frac{3}{5}}$ & Total & $\%$ \\
\hline Lung & 19 & 15 & 11 & 2 & 2 & 1 & 1 & 6 & 1 & 0 & 58 & 27.88 \\
\hline Tracheal swap & 6 & 8 & 5 & 0 & 0 & 0 & 0 & 3 & 1 & 0 & 23 & 11 \\
\hline Liver & 14 & 9 & 10 & 1 & 0 & 0 & 0 & 4 & 0 & 0 & 38 & 18.26 \\
\hline Kidney & 9 & 16 & 9 & 1 & 0 & 0 & 1 & 6 & - & 1 & 43 & 20.6 \\
\hline Heart & 16 & 5 & 6 & 1 & 1 & 0 & 0 & 5 & 0 & 0 & 34 & 16.34 \\
\hline Litter & 4 & 3 & 2 & 0 & 0 & 0 & 0 & 3 & 0 & 0 & 12 & 5.76 \\
\hline Total & 68 & 56 & 43 & 5 & 3 & 1 & 2 & 27 & 2 & 1 & 208 & \\
\hline$\%$ & 32.7 & 26.9 & 20.6 & 2.4 & 1.4 & 0.48 & 0.96 & 12.9 & 0.96 & 0.48 & & \\
\hline
\end{tabular}

Table 3. Screening of fungal isolates for Heamolysin, catalase, lipase, amylase, biofilm production in a total of 208 fungal isolates.

\begin{tabular}{|c|c|c|c|c|c|c|c|c|c|c|c|}
\hline \multirow[t]{2}{*}{ Fungal isolates } & \multirow{2}{*}{$\begin{array}{l}\text { Number } \\
\text { isolates }\end{array}$} & \multicolumn{2}{|c|}{ Hemolysis } & \multicolumn{2}{|c|}{ Catalase } & \multicolumn{2}{|c|}{ Amylase } & \multicolumn{2}{|c|}{ Lipase } & \multicolumn{2}{|c|}{ Biofilm } \\
\hline & & No. & $\%$ & No. & $\%$ & No. & $\%$ & No. & $\%$ & No. & $\%$ \\
\hline A.fumigatus & 68 & 15 & 22 & 31 & 45.5 & 45 & 66 & 32 & 47 & 59 & 86.7 \\
\hline A.niger & 56 & 22 & 39 & 32 & 57 & 36 & 64 & 37 & 66 & 44 & 78,5 \\
\hline A.flavus & 43 & 8 & 18.6 & 26 & 60 & 21 & 46.8 & 25 & 58 & 34 & 79 \\
\hline A.terrus & 5 & 0 & $\begin{array}{l}0.0 \\
\text { buy0 }\end{array}$ & 1 & 20 & 0 & 0.00 & 1 & 20 & 1 & 20 \\
\hline A.nidulance & 1 & 0 & 0.00 & 0 & 0.00 & 0 & 0.00 & 0 & 0.00 & 0 & 0.00 \\
\hline A.glaucus & 3 & 0 & 0.00 & 0 & 0.00 & 1 & 33 & 0 & 0.00 & 0 & 0.00 \\
\hline Total aspergillus & 177 & 45 & 25.42 & 90 & 50.85 & 103 & 58.19 & 95 & 53.67 & 139 & 78.53 \\
\hline Acremonium & 2 & 0 & 0.00 & 0 & 0.00 & 2 & 100 & 0 & 0.00 & 1 & 50 \\
\hline Zygomycetes & 27 & 9 & 33 & 27 & 100 & 9 & 33 & 3 & 11 & 4 & 14,8 \\
\hline Penicillium & 2 & 0 & 0.00 & 1 & 50 & 2 & 100 & 0 & 0.00 & 1 & 50 \\
\hline Alternaria & 1 & 0 & 0.00 & 0 & 0.00 & 0 & 0.00 & 0 & 0.00 & 0 & 0.00 \\
\hline
\end{tabular}


Table 4. The distribution of virulence genes in the tested fungal isolates (49) tested

$\begin{array}{lllll}\text { SPP } & \text { Number of isolates } & f o s-1 & p k s P & \text { rhbA } \\ \text { A. Fumigatus } & 9 & 3 & 7 & 8 \\ \text { A. Flavus } & 9 & 2 & - & 1 \\ \text { A. Niger } & 8 & - & 2 & - \\ \text { A. Terrus } & 5 & - & - & - \\ \text { A. Glaucus } & 3 & - & - & - \\ \text { A. Nidulance } & 1 & - & - & - \\ \text { Acremonium } & 2 & - & - & - \\ \text { Zygomycetes } & 9 & - & - & - \\ \text { Penicillium } & 2 & - & - & - \\ \text { Alternaria } & 1 & - & - & -\end{array}$

Table 5. Minimal inhibitory concentration of the tested isolates against antifungal agents.

\begin{tabular}{|c|c|c|c|c|c|c|c|c|}
\hline \multirow[t]{2}{*}{ Drug } & \multicolumn{6}{|c|}{ Aspergillus } & \multirow{2}{*}{$\begin{array}{l}\text { Acremo- } \\
\text { nium }\end{array}$} & \multirow{2}{*}{$\begin{array}{l}\text { Zygomyc- } \\
\text { etes }\end{array}$} \\
\hline & Fumigatus & Niger & Flavus & Terrus & Glaucus & Nidiulance & & \\
\hline Clotrimazole & $500 \mu \mathrm{g} / \mathrm{ml}$ & $125 \mu \mathrm{g} / \mathrm{ml}$ & $125 \mu \mathrm{g} / \mathrm{ml}$ & resist & $250 \mu \mathrm{g} / \mathrm{ml}$ & resist & $1000 \mu \mathrm{g} / \mathrm{ml}$ & $1000 \mu \mathrm{g} / \mathrm{ml}$ \\
\hline Tioconazole & Resist & Resist & $1000 \mu \mathrm{g} / \mathrm{ml}$ & $125 \mu \mathrm{g} / \mathrm{ml}$ & $1000 \mu \mathrm{g} / \mathrm{ml}$ & $1000 \mu \mathrm{g} / \mathrm{ml}$ & resist & Resist \\
\hline $\begin{array}{l}\text { Ciclopiroxola } \\
\text { mine }\end{array}$ & $500 \mu \mathrm{g} / \mathrm{ml}$ & $500 \mu \mathrm{g} / \mathrm{ml}$ & $1000 \mu \mathrm{g} / \mathrm{ml}$ & $125 \mu \mathrm{g} / \mathrm{ml}$ & Resist & resist & resist & Resist \\
\hline Fluconazole & \multicolumn{6}{|c|}{ Resist } & $1000 \mu \mathrm{g} / \mathrm{ml}$ & Resist \\
\hline Nystatine & \multicolumn{8}{|c|}{ Resist } \\
\hline
\end{tabular}

\section{DISCUSSION}

Mycotic infection in poultry is considered one of the most severe problems affecting poultry resulted in high economic losses due to high morbidity and mortality in young chicken as well as immunosuppression in birds. Mycotic diseases can be expected due to the extensive use of antibiotics preparations in the treatment of many diseases and as feed additives, which enhance mycotic complications.

Litter is one of the primary sources responsible for fungal contamination in poultry farms [32]. The process of spreading of litter or after being used and removed from poultry farms represents a serious hazard to the farmworker due to frequent exposure to dust, fungi, and their metabolites during their task $[33,34]$. Therefore, it is crucial to identify mycoflora of poultry litter to recognize the possibility of occupational exposure of poultry workers to the pathogenic fungal species.

By mycological examination of chicken samples, 196 fungal isolates have been recovered. The prevalence of fungi was higher in lung tissue (27.88\%) comparing to the other examined samples, similar to what obtained by Sajid et al. [35] and Abdeltawab et al. [36]. Aspergillus was the most common genus recovered (84.61\%), followed by Zygomycetes (12.9\%). In addition to previously mentioned species, other genera were also isolated, namely,
Acremonium, Penicillium (0.96\% each), and Alternaria $(0.48 \%)$ (Table 2). Among Aspergillus genus isolates, $A$. fumigatus was the most frequent $(32.96 \%)$ followed by $A$. niger $(26.92 \%)$ then $A$. flavus $(20.6 \%)$. The reason for the variations in different studies may be due to sample size, environment factors, seasonal variation, nutrition requirements, and virulence factors of these fungi [37].

Aspergillus fumigatus was common isolates from both chicks' organs and litter samples. Aspergillosis has been described either as an acute infection leading to severe outbreaks in young birds or as a chronic condition responsible for low productivity and economic losses in adult birds. Aspergillosis should be suspected when birds suffered from debilitation, respiratory distress, without response to antibiotics treatment . The incidence of $A$. fumigatus infection is usually higher in poultry as the spores of this species are smaller than those of other species of Aspergillus [38]. But the role of other Aspergillus species that may affect birds couldn't be ignored [39].

Concerning litter, out of Seven litter samples collected from 7 poultry farms, twelve fungal isolates were recovered, including four fungal species identified as $A$. fumigatus (4 isolates), A. niger (3 isolates), A.flavus (3 isolates) and three isolates of Zygomycetes. These findings were in line with Anbu et al. [40], who stated the most prevalent species 
isolated in the litter were Fusarium solani, $A$. nidulans $A$. flavus, $A$. niger, and other fungal genera. On the other hand, Viegas et al. [41] reported Penicillium as the most prevalent isolate from poultry litter in addition to Aspergillus species. The diversity of litter mycoflora may be contributed to the material choice, litter aging, and handling techniques [42].

The presence of virulence factors confirmed the pathogenicity of the isolates. Pathogenesis of aspergillosis is dependent on various factors of the host (immune status) and virulence factors of the pathogen. The principal mode of action of these virulence factors is as follows cause degradation of tissue carbohydrate ( $\alpha$-amylase) and lipids (lipase), Haemolysin causes lysis of red blood cells [43]. Catalase helps in detoxification of reactive oxygen species (ROS) produced by macrophages and neutrophils [44]. Aspergillus catalase plays a potential role in allowing the organism to escape or to minimize hyphal damage by inactivating hydrogen peroxide [45]. Higher prevalence of enzymatic activity was recorded in a study conducted by Zohri et al. [26], where out of eighty isolates of Aspergillus species, all of the tested isolates were able to produce catalase and peroxidase enzymes. Meanwhile, $82.5-90 \%$ of the fungal isolates could produce protease, lipase, urease, and phospholipase. Whereas $70 \%$ of isolates exhibited hemolytic activities. In another study, out of 110 tested isolates 73, 92, and 78 produced protease, lipase, and urease, respectively; meanwhile, 77 of the tested isolates exhibited some hemolytic activities [46].

Interestingly the overall prevalence of the assessed virulence factors, the prevalence was found more in Aspergillus species, especially A.fumigatus isolated from chicks samples then environmental samples; this could be due to invasiveness nature of Aspergilli.

In addition to the evaluated extracellular hydrolytic enzymes in fungal isolate, we used PCR assay for the detection of genes responsible for the virulence of fungi. Three genes were targeted to be tested with PCR. (fos-1, $p k s P$, and $r h b A$ ) which are involved in aspergillus infection such as evasion from the immune response, and the conidial melanin-DHN (pksP/alb1 gene). Our results revealed that fos1 was detected in A.fumigatus (3) and A.flavus (2). While pks $P$ detected in A.fumigatus (7) and A.niger (2). rhbA detected in A.fumigatus (8) and A.flavus (1). The detection of such genes in our isolates confirms the pathogenicity of these species and their important role in pathogenicity.

Many different studies have demonstrated that fungal biofilms show increased levels of resistance against many classes of antifungal drugs, especially azoles and polyenes [47]. Studying the ability of biofilm formation is very important as the incidence of mycotic infections has dramatically increased nowadays, which is frequently associated with biofilm formation on implanted biomaterials and/or host surfaces [48]. In this study biofilm production as revealed by $86.7 \%$ (59/68) A. fumigatus , $78.5 \%(44 / 56)$ A.niger,79\% (34/43) A.flavus, 20\% (1/5) A.terreus, 50\%(1/2) Acremonium, 14.8\%(4/27) 50\% (1/2) Penicillium.
In this study, we investigated the in-vitro efficacy of antifungals against five representative fungal isolates from diseased chicken and litter cases using microdilution assays. As is the case of bacteria, no single antifungal was most effective for all fungi. Clotrimazole has the lowest MIC against A.niger and A. terreus. Tioconazole has the lowest activity against A.terreus. Ciclopiroxolamine also has the lowest MIC against A.terreus. Mostly all isolates were resistant to fluconazole and nystatin. Long-term use of azole drugs for aspergillosis is the major reason for the emergence of azole resistance [49]. Also, the improper use of fungicides in agriculture results in the increase in azole resistance $[16,50]$. Interestingly, the high resistant to fluconazole explained also by Odds et al. [51] who found that in vitro susceptibility tests in new triazole and fluconazole did not accurately reflect the therapeutic efficacy while the activity of fluconazole in vivo animal model infection was found to be several times greater than the predicted in vitro measures. Besides, earlier studies showed that $A$. fumigatus that resistant to antifungals was observed has the capability of biofilm formation [52].

The MIC determination provides an evidence for nystatin treatment failures in clinical cases of aspergillosis and other isolates. The best effective drug on isolates is clotrimazole followed by ciclopiroxolamine and tioconazole. Following the current study, Guarro et al. [53] confirmed that Acremonium spp. are generally resistant to the most commonly used antifungal agents.

\section{Conclusion}

In conclusion, Effective prevention of mycotic infections throughminimization of stress factors, strict hygienic measures, good litter management practice, and sanitation in brooders and hatcheries should be considered. Control measures like strict biosecurity program, and regular monitoring of fungal infections as well as appropriate use of anti-fungal drugs Should be followed.

\section{Acknowledgment}

\section{Conflict of interest statement}

No conflict of interest was declared.

\section{Research Ethics Committee Permission}

The current research work is permitted to be executed according to standards of Research Ethics committee, Faculty of Veterinary Medicine, Mansoura University.

\section{Authors' contribution}

SM collected samples and carried out the experiments; AA wrote the manuscript and shared with SM in conducting experiments, and GY designed the study and reviewed the manuscript. All authors approved the final manuscript for publication. 


\section{REFERENCES}

1. Dhama K, Chakraborty S, Verma AK, Tiwari R, Barathidasan R, Kumar A, et al. Fungal/mycotic diseases of poultry-diagnosis, treatment and control: a review. Pakistan J BiolSci 2013;16:1626-40. https://doi.org/10.3923/pjbs.2013.1626.1640

2. Binder $U$, Lass-Flörl $C$. Epidemiology of invasive fungal infections in the mediterranean area. Mediterr J Hematol Infect Dis 2011; 3(1) e20110016.

\section{https://doi.org/10.4084/mjhid.2011.016}

3. Zafra R, Pérez J, Pérez-Écija R, Borge C, Bustamante R, Carbonero A, et al. Concurrent aspergillosis and ascites with high mortality in a farm of growing broiler chickens. Avian diseases 2008;52:711-3. https://doi.org/10.1637/8283-031208-Case.1

4. Martin MP, Pecelunas Bouck K, Helm J, Dykstra MJ, Wages DP, Barnes HJ. Disseminated Aspergillus flavus infection in broiler breeder pullets. Avian Dis 2007;51:626-31. https://doi.org/10.1637/00052086(2007)51[626:DAFIIB]2.0.CO;2

5. Kunkle R, Saif Y, Barnes H, Glisson J. Aspergillosis, Diseases of Poultry. Eds., pp. 883-895, lowa State University Press, Ames, lowa, USA, 11th edition, 2003

6. Casadevall A. Determinants of virulence in the pathogenic fungi. Fungal Biol Rev 2007;21: 130-132. https://doi.org/10.1016/j.fbr.2007.02.007

7. Ibrahim AS, Mirbod F, Filler SG, Banno Y, Cole GT, Kitajima Y, et al. Evidence implicating phospholipase as a virulence factor of Candida albicans. Infect Immun 1995;63:1993-8. https://doi.org/10.1128/IAI.63.5.1993-1998.1995

8. Da Silva B, Auler M, Ruiz LdS, Gandra R, Dos Santos J, Paula C, et al. Trichophyton rubrum isolated from AIDS and human immunodeficiency virus-infected patients in São Paulo, Brazil: antifungal susceptibility and extracellular enzyme production. Chemotherapy 2005;51:21-6. https://doi.org/10.1159/000084019

9. Tomee J, Kauffman H. Putative virulence factors of Aspergillus fumigatus. Clin Exp Allergy 2000;30:476-84. https://doi.org/10.1046/j.13652222.2000.00796.x

10. Denning D, Marinus A, Cohen J, Spence D, Herbrecht R, Pagano L, et al An EORTC multicentre prospective survey of invasive aspergillosis in haematological patients: diagnosis and therapeutic outcome. J Infect 1998;37:173-80. https://doi.org/10.1016/S0163-4453(98)80173-4

11. Tsai H-F, Chang YC, Washburn RG, Wheeler MH, Kwon-Chung K. The Developmentally Regulated alb1 Gene ofAspergillus fumigatus: Its Role in Modulation of Conidial Morphology and Virulence. J Bacteriol 1998;180:3031-8. https://doi.org/10.1128/JB.180.12.3031-3038.1998

12. Panepinto JC, Oliver BG, Amlung TW, Askew DS, Rhodes JC. Expression of the Aspergillus fumigatus rheb homologue, rhbA, is induced by nitrogen starvation. Fungal Genet Biol 2002;36):207-14. https://doi.org/10.1016/S1087-1845(02)00022-1

13. Panepinto JC, Oliver BG, Fortwendel JR, Smith DL, Askew DS, Rhodes JC. Deletion of the Aspergillus fumigatus gene encoding the Ras-related protein RhbA reduces virulence in a model of invasive pulmonary aspergillosis. Infect Immun 2003;71:2819-26. https://doi.org/10.1128/IAI.71.5.2819-2826.2003

14. Jesline A, John NP, Narayanan P, Vani C, Murugan S. Antimicrobial activity of zinc and titanium dioxide nanoparticles against biofilmproducing methicillin-resistant Staphylococcus aureus. Appl Nanosci 2015;5:157-62. https://doi.org/10.1007/s13204-014-0301-x

15. Alastruey-Izquierdo A, Melhem MS, Bonfietti LX, Rodriguez-Tudela JL. Susceptibility test for fungi: clinical and laboratorial correlations in medical mycology. Revista do Instituto de Medicina Tropical de São Paulo 2015;57:57-64. https://doi.org/10.1590/S003646652015000700011

16. Seidler MJ, Salvenmoser S, Müller F-MC. Aspergillus fumigatus forms biofilms with reduced antifungal drug susceptibility on bronchial epithelial cells.Antimicrob Agents Chemother2008;52:4130-6. https://doi.org/10.1128/AAC.00234-08

17. Villena GK, Venkatesh L, Yamazaki A, Tsuyumu S, Gutiérrez-Correa M. Initial intracellular proteome profile of Aspergillus niger biofilms. Revista Peruana de Biología 2009;16:101-8.

18. Bruns S, Seidler M, Albrecht D, Salvenmoser S, Remme N, Hertweck C, et al. Functional genomic profiling of Aspergillus fumigatus biofilm reveals enhanced production of the mycotoxin gliotoxin. Proteomics 2010;10:3097-107. https://doi.org/10.1002/pmic.201000129
19. Kaur S, Singh S. Biofilm formation by Aspergillus fumigatus. Medical mycology.

2013;52:2-9 https://doi.org/10.3109/13693786.2013.819592

20. Paul S, Ludeña Y, Villena GK, Yu F, Sherman DH, Gutiérrez-Correa M High-quality draft genome sequence of a biofilm forming lignocellulolytic Aspergillus niger strain ATCC 10864. Stand Genomic Sci.2017;12:37. https://doi.org/10.1186/s40793-017-0254-2

21. Midgley G, Clayton Y, Hay J. Diagnosis in color medical mycology, international. Mosby, UK. 1997:14-7.

22. Ellis DH, Davis S, Alexiou H, Handke R, Bartley R. Descriptions of medical fungi: University of Adelaide Adelaide; 2007. Australia 2nd edition,

23. Manns JM, Mosser DM, Buckley HR. Production of a hemolytic factor by Candida albicans. Infect Immun 1994;62:5154-6. https://doi.org/10.1128/IAI.62.11.5154-5156.1994

24. Mezher MA, Bandar KI. Identification study some virulence factors of invasive mold infections isolated from patients undergoing chemotherapy in Tikrit teaching Hospital. Egypt Acad J Biolog Sci 2015;7:1-11. https://doi.org/10.21608/eajbsg.2015.16480

25. Oyeleke SB, Oyewole O, Egwim E. Production of protease and amylase

from Bacillus subtilis and Aspergillus niger using Parkia biglobossa (Africa

Locust Beans) as substrate in solid state fermentation. Advances in Life

Sciences 2011; 1(2): 49-53 DOI: 10.5923/j.als.20110102.09

26. Zohri A, Aboul-Nasr M, Adam M, Mustafa M, Amer E. Impact of enzymes and toxins potentiality of four aspergillus species to cause aspergillosis. Biol Med (Aligarh). 2017;9(5):1-7.

27. Alapont C, Martínez-Culebras $P$, López-Mendoza M. Determination of lipolytic and proteolytic activities of mycoflora isolated from dry-cured teruel ham. J Food Sci Technol 2015;52:5250-6. https://doi.org/10.1007/s13197-014-1582-5

28. Dag I, Kiraz N, Oz Y. Evaluation of different detection methods of biofilm formation in clinical Candida isolates. AFR J MICROBIOL RES. 2010;4:2763-8.

29. Ochei JO, Kolhatkar AA. Medical laboratory science: theory and practice, Tata McGraw-Hill Education Pvt. Ltd., 1st edition, New York,2000.

30. Agbulu C, Iwodi C, Onekutu A. In vitro Susceptibility Test of Some Antifungal Drugs on Selected Dermatophytes and Yeasts Isolated from Patients Attending Hospitals in Makurdi Environ. Microbiol J 2015;5:916. https://doi.org/10.3923/mj.2015.9.16

31. Zhang L, Wang M, Li R, Calderone R. Expression of Aspergillus fumigatus virulence-related genes detected in vitro and in vivo with competitive RT-PCR. Mycopathologia. 2005;160:201-6. https://doi.org/10.1007/s11046-005-0141-z

32. Williams CM. Poultry waste management in developing countries. the role of poultry in human nutrition 2013: Food and Agriculture Organization of the United Nations (FAO).

33. Whyte RT. Occupational exposure of poultry stockmen in current barn systems for egg production in the United Kingdom. British Poultry Science.

2002:43:364-73. https://doi.org/10.1080/00071660120103639

34. Tsapko VG, Chudnovets AJ, Sterenbogen MJ, Papach VV, Dutkiewicz J, Skorska C, et al. Exposure to bioaerosols in the selected agricultural facilities of the Ukraine and Poland - a review. Ann Agric Environ Med. 2011;18:19-27.

35. Sajid M, Khan I, Rauf U. Aspergillus fumigatus in commercial poultry flocks, a serious threat to poultry industry in Pakistan. J Anim Plant Sci 2006;16.

36. Abdeltawab A, Maarouf A, El-Hofy F, Khalid S. Molecular characterization of some fungi isolated from broiler chicken farms. BVMJ. 2015;29:10618. https://doi.org/10.21608/bvmj.2015.31682

37. Cooke NS, Feighery C, Armstrong DK, Walsh M, Dempsey S. Cutaneous Fusarium solani infection in childhood acute lymphoblastic leukaemia. Clin Exp Dermatol 2009;34:e117-9. https://doi.org/10.1111/j.13652230.2008.03164.x

38. Arné $P$, Thierry S, Wang $D$, Deville $M$, Loc'h L, Desoutter A, et al. Aspergillus fumigatus in poultry. Int J Microbiol 2011;2011. https://doi.org/10.1155/2011/746356

39. Beernaert LA, Pasmans F, Van Waeyenberghe L, Haesebrouck F, Martel A. Aspergillus infections in birds: a review. Avian Pathol 2010;39:325-31. https://doi.org/10.1080/03079457.2010.506210

40. Anbu P, Hilda A, Gopinath SCB. Keratinophilic fungi of poultry farm and feather dumping soil in Tamil Nadu, India. Mycopathologia 2004;158:303-9. https://doi.org/10.1007/s11046-004-3465-1 
41. Viegas C, Carolino E, Malta-Vacas J, Sabino R, Viegas S, Verissimo C. Fungal contamination of poultry litter: a public health problem. J Toxicol Environ Health A 2012;75:1341-50. https://doi.org/10.1080/15287394.2012.721165

42. Dennis C, GEE JM. The microviral flora of broiler-house litter and dust. J Gen Microbiol 1973;78:101-7. https://doi.org/10.1099/00221287-78-1101

43. Loussert C, Schmitt C, Prevost MC, Balloy V, Fadel E, Philippe B, et al. In vivo biofilm composition of Aspergillus fumigatus. Cell Microbiol 2010;12:405-10. https://doi.org/10.1111/j.1462-5822.2009.01409.x

44. Paris S, Wysong D, Debeaupuis JP, Shibuya K, Philippe B, Diamond RD, et al. Catalases of Aspergillus fumigatus. Infect Immun 2003;71:3551-62. https://doi.org/10.1128/IAI.71.6.3551-3562.2003

45. Takasuka T, Sayers NM, Anderson MJ, Benbow EW, Denning DW. Aspergillus fumigatus catalases: cloning of an Aspergillus nidulans catalase B homologue and evidence for at least three catalases. FEMS Immunol Med Microbiol 1999;23:125-33. https://doi.org/10.1111/j.1574-695X.1999.tb01231.x

46. Aboul-Nasr MB, Zohri A-NA, Amer EM. Enzymatic and toxigenic ability of opportunistic fungi contaminating intensive care units and operation rooms at Assiut University Hospitals, Egypt. SpringerPlus 2013;2:347. https://doi.org/10.1186/2193-1801-2-347

47. Ramage G, Saville SP, Thomas DP, Lopez-Ribot JL. Candida biofilms: an update. Eukaryot Cell. 2005;4:633-8. https://doi.org/10.1128/EC.4.4.633-638.2005
48. Pierce CG, Uppuluri P, Tristan AR, Wormley FL, Jr., Mowat E, Ramage G, et al. A simple and reproducible 96-well plate-based method for the formation of fungal biofilms and its application to antifungal susceptibility testing. Nat Protoc 2008;3:1494-500. https://doi.org/10.1038/nprot.2008.141

49. Hagiwara D, Watanabe A, Kamei K, Goldman GH. Epidemiological and Genomic Landscape of Azole Resistance Mechanisms in Aspergillus Fungi. Front Microbiol 2016;7:1382. https://doi.org/10.3389/fmicb.2016.01382

50. Chowdhary A, Kathuria S, Xu J, Meis JF. Emergence of azole-resistant aspergillus fumigatus strains due to agricultural azole use creates an increasing threat to human health. PLoS pathogens2013;9(10):e1003633-e. https://doi.org/10.1371/journal.ppat.1003633

51. Odds FC, Cheesman SL, Abbott AB. Antifungal effects of fluconazole (UK 49858), a new triazole antifungal, in vitro. J Antimicrob Chemother 1986;18:473-8. https://doi.org/10.1093/jac/18.4.473

52. Mowat E, Butcher J, Lang S, Williams C, Ramage G. Development of a simple model for studying the effects of antifungal agents on multicellular communities of Aspergillus fumigatus. J Med Microbiol2007;56:1205-12. https://doi.org/10.1099/jmm.0.47247-0

53. Guarro J, Gams W, Pujol I, Gene J. Acremonium species: new emerging fungal opportunists--in vitro antifungal susceptibilities and review. Clin Infect Dis 1997;25:1222-9. https://doi.org/10.1086/516098 